\title{
Outpatient transplants: American standard in Poland
}

\author{
Andrzej J. Jakubowiak \\ Biological Sciences Division, University of Chicago Medical Center, Chicago, IL, USA
}

Dytfeld et al. [1] describe a very promising pilot program for the early discharge of patients undergoing autologous stem cell transplant (ASCT). This is an important step towards fully outpatient procedures, which have become increasingly common in the USA.

ASCT is recommended as a standard of care for all eligible multiple myeloma ( $\mathrm{MM}$ ) patients and is commonly used as a salvage treatment for lymphoma. At our center, and at other centers in the USA, ASCT has become available for some patients on an outpatient basis. Our outpatient transplant program is now close to 7-years-old, and has grown to become very successful. With the proper organizational steps, every year we have been increasing the proportion of patients qualified for outpatient ASCT.

Based on our analysis, patients and staff are not only comfortable, but also universally happy, with participation in outpatient transplant management, taking great comfort from spending nights at home, which significantly increases their overall quality of life. However, the benefits are not limited to patient experience. Another benefit we have seen is that the outpatient approach simplifies management and decreases workload for our providers. With short, daily follow-up visits in our outpatient transplant unit attended by members of the transplant team, the process is streamlined, and patients have daily continuity of care by a specialized team, or, if needed, immediate access to inpatient care. While the coronavirus disease 2019 (COVID-19) epidemic has affected many hospital operations including outpatient ASCT, with the anticipated return to normalcy, moving with ASCT toward an outpatient setting will have a large impact on lowering bed occupancy. Not unimportantly, costs associated with outpatient transplants in our US healthcare environment are significantly lower than for fully inpatient transplants. It is likely that outpatient transplants could generate cost savings and bed occupancy savings as seen in other countries including Poland.

Though the literature to date shows no difference in safety and efficacy between outpatient and inpatient transplants [2-4], it is important to conduct further studies. We must not separate convenience and safety. It will be important to demonstrate in a larger study expanded to other centers that the same benefits can be achieved in the European healthcare system. Administrative steps will be important, and likely needed, in expanding early discharge programs into fully outpatient autologous transplant procedures.

\section{Authors' contributions}

AJJ - sole author.

\section{Conflict of interest}

None.

\section{Financial support \\ None.}

\section{Ethics}

The work described in this article has been carried out in accordance with the Code of Ethics of the World Medical Association (Declaration of Helsinki) for experiments involving humans; EU Directive 2010/63/EU for animal experiments; Uniform Requirements for Manuscripts submitted to Biomedical Journals.

\section{References}

1. Dytfeld D, Łojko-Dankowska A, Nowicki A, et al. Safety and cost effectiveness of outpatient autologous hematopoietic stem cell transplantation for multiple myeloma - single center experience of a pilot Early Discharge Program. Acta Haematol Pol. 2021; 52(3): 178-181, doi: 10.5603/AHP.a2021.0029.
Address for correspondence: Andrzej J. Jakubowiak, Biological Sciences Division, University of Chicago Medical Center, 5841 S Maryland Avenue, Chicago, IL 60637, USA, phone: +1 773702 4632, e-mail: ajakubowiak@medicine.bsd.uchicago.edu

\footnotetext{
PTHiT Copyright (C) 2021 The Polish Society of Haematologists and Transfusiologists, Insitute of Haematology and Transfusion Medicine. All rights reserved.
} 
2. Holbro A, Ahmad I, Cohen S, et al. Safety and cost-effectiveness of outpatient autologous stem cell transplantation in patients with multiple myeloma. Biol Blood Marrow Transplant. 2013; 19(4): 547-551, doi: 10.1016/j.bbmt.2012.12.006, indexed in Pubmed: 23253556.

3. Martino M, Lemoli RM, Girmenia C, et al. Italian consensus conference for the outpatient autologous stem cell transplantation management in multiple myeloma. Bone Marrow Transplant. 2016;
51(8): 1032-1040, doi: 10.1038/bmt.2016.79, indexed in Pubmed: 27042841

4. Faucher C, Le Corroller Soriano AG, Esterni B, et al. Randomized study of early hospital discharge following autologous blood SCT: medical outcomes and hospital costs. Bone Marrow Transplant. 2012; 47(4): 549-555, doi: 10.1038/bmt.2011.126, indexed in Pubmed: 21725375 . 